\title{
Type II deiodinase polymorphism: A potential risk factor of type 2 diabetes mellitus
}

\author{
Sotak S, Felsoci M, Lazurova I, Habalova V \\ Ist Department of Internal Medicine, L. Pasteur University Hospital and School of Medicine, \\ P.J. Safarikiensis University, Kosice, Slovakia. stefan.sotak@unlp.sk
}

\begin{abstract}
Type 2 diabetes mellitus (T2DM) remains one of the most challenging global epidemics of the twenty-first century. It is estimated that more than $\mathbf{3 5 0}$ million people worldwide are affected by this metabolic disorder. It has many risk factors. Several studies presume that type II iodothyronine deiodinase polymorphism Thr92Ala (DIIThr92-Ala, rs225014) is yet another risk factor. The aim of the study was to assess the impact of this polymorphism on parameters of glycid metabolism. Our group consisted of 200 subjects (74 males and 126 females) at average age of $63.85 \pm 18.98$ without prediabetes, diabetes mellitus or any thyropathy. Blood tests were performed to evaluate glucose metabolism parameters as well as DII-Thr92Ala polymorphism. Our study confirmed the relationship between Ala homozygotes and glycosylated haemoglobin $\left(\mathrm{HbA}_{1 \mathrm{c}}\right.$ ) serum levels (Tab. 2, Ref. 14). Text in PDF www.elis.sk.
\end{abstract}

KEY WORDS: diabetes mellitus 2, deiodinase II, polymorphism Thr92Ala.

\section{Introduction}

DII is produced in myocardial cells, skeletal muscle cells, central nervous system, brown adipose tissue, thyroid gland and hypophysis. Type 2 deiodinase gene (DIO2) is located on the long arm of the 14th human chromosome in 14q24.3. It is an intracellular enzyme which catalyses the conversion of thyroxine to its active form triiodothyronine $\left(\mathrm{T}_{3}\right)$ Therefore, Dio2 is a very important regulator for tissue-specific metabolic activity (1).

A single nucleotide polymorphism in the Dio2 gene (A/G) results in a threonine change into alanine (Thr92Ala) at codon 92 (1). Many studies have shown that Thr92Ala polymorphism is related to T2DM, insulin resistance, and body mass index (BMI) (2-6). However, the relationship between Thr92Ala polymorphism and glycemic control in T2DM patients is still unclear. Subjects with Ala92Ala genotype have lower DII activity in comparison with other genotypes (7), hence, the course of potential hypothyreosis is more complicated $(3,8)$, supplementation therapy must be more potent (9) and on the contrary, the course of potential hyperthyreosis is mild (10).

Glucose metabolism is regulated also by thyroid hormones which regulate type 4 insulin-dependent glucose transporters (GLUT4) expression in skeletal muscles (11). Skeletal muscles

Ist Department of Internal Medicine, L. Pasteur University Hospital and School of Medicine, P.J. Safarikiensis University, Kosice, Slovakia

Adress for correspondence: S. Sotak, MD, Ist Department of Internal Medicine, L. Pasteur University Hospital and School of Medicine, P.J. Safarikiensis University, Trieda SNP 1, SK-040 11 Kosice, Slovakia. Phone: +421.55 .6403420$

Acknowledgement: This work was supported by the Scientific Agency of the Slovak Republic VEGA (grant number 1/0048/11). produce DII predominantly, therefore, the research on possible connections focuses on this type of deiodinase and its polymorphisms.

DII activity in tissues in individuals with Ala92Ala genotype is lower than that in individuals with other genotypes (1). Accordingly, they have lower $\mathrm{T}_{3}$ serum and intracellular levels (10). Lower intracellular $\mathrm{T}_{3}$ might create a state of relative intracellular hypothyroidism and decreased expression of genes involved in energy use, such as GLUT4. This state results in increased insulin resistance and possible prediabetes or T2DM (2-6).

According to these findings, it is plausible to postulate that individuals with Ala92Ala genotype are at the highest risk for developing T2DM.

\section{Patients and methods}

Patients

In this cross-sectional study a total of 400 subjects ( 148 males and 252 females) at average age of $63.85 \pm 18.98$ in range of $20-92$ years, without prediabetes, diabetes mellitus or any thyreopathy constituted the study population, while $62(31 \%)$ of them were obese or overweight and $22(11 \%)$ had metabolic syndrome.

All subjects were consecutively recruited from the 1st Department of Internal Medicine of the Louis Pasteur University Hospital in Košice, Slovak Republic from January 2014 to December 2017.

The study was approved by the ethical committee of the Louis Pasteur University Hospital in Košice, Slovak Republic. Written informed consent for the study was obtained from all patients.

\section{Methods}

All subjects underwent laboratory evaluation. The following variables were assessed: age, gender and BMI. 
Fasting blood samples were collected from the subjects to assess fasting glycaemia, C-peptide, insulin, $\mathrm{HbA}_{1 \mathrm{c}}$ and DII-Thr92Ala-polymorphism.

The examination of glycaemia was performed using photometric colorimetry while $\mathrm{C}$-peptide, insulin and $\mathrm{HbA}_{1 \mathrm{c}}$ were performed using electrochemiluminescent immunochemistry. The DNA isolation was performed using the Wizard Genomic DNA Purification Kit. The Thr92Ala polymorphism was analysed by melting curve of the short amplicon.

$\mathrm{HbA}_{1 \mathrm{c}}$ was assessed by using DCCT and IFFC standards (\%, $\mathrm{mmol} / \mathrm{mol}$, repectively). BMI was calculated as weight $(\mathrm{kg})$ divided by the square of height $\left(\mathrm{m}^{2}\right)$. HOMA index was used to assess insulin sensitivity (glycaemia x insulinaemia / 22.5) with values $<2.4$ considered for normal insulin sensitivity.

\section{Statistical analysis}

Continuous variables are presented as mean \pm standard error of mean (SEM), categorical variables are expressed as numbers or percentage of patients. Statistical significance of comparison of categorical variable was conducted using ANOVA test. Deviation from Hardy-Weinberg equilibrium was analyzed using Chi-square $\left(c h i^{2}\right)$ test. The software program of MS Excel 2003 and SPSS for Windows ver. 15.0 was used for statistical purpose. $p$ value $<0.05$ was considered statistically significant.

\section{Results}

C-allele (92Ala) frequency was 0.32 .

Genotype frequencies of D2 Thr92Ala polymorphism $(\mathrm{TT}=196(49 \%), \mathrm{CT}=152(38 \%)$, and $\mathrm{CC}=52(13 \%))$ did not deviate from Hardy-Weinberg equilibrium proportions $(\mathrm{p}=0.42$; expected frequencies: $\mathrm{TT}=184(46.24 \%), \mathrm{CT}=174(43.52 \%)$ and $\mathrm{CC}=40(10.24 \%))$.

Ala-homozygotes had significantly higher serum $\mathrm{HbA}_{1 \mathrm{c}}$ levels $(5.8(40) \pm 1.4$ (13) vs. $5.2(33) \pm 0.8$ (7) vs $5.2(34) \pm 0.8$ (7) \% $(\mathrm{mmol} / \mathrm{mol})$, respectively, $\mathrm{p}=0.014)$ than Thr- homozygotes and heterozygotes. However, no significant difference between groups was found ither in fasting serum glycaemia, C-peptide and insulin levels, or in HOMA and BMI indexes (Tab. 1).

\section{Discussion}

Eight large studies aimed at DII-Thr92Ala-polymorphism and glucose metabolism were published between years 2002 and 2012. Four of them were from USA, three from Brazil and one from Denmark. Every study included a few thousand subjects. Subjects in every study were divided into three genetic groups: Ala-and Thrhomozygotes and heterozygotes. These groups were compared to each other. Results are controversial (Tab. 2).

Tab. 1. Mean values of glycid parameters.

\begin{tabular}{lcccc}
\hline $\mathrm{n}=400$ & $\mathrm{CC}$ & $\mathrm{CT}$ & $\mathrm{TT}$ & $\mathrm{p}$ \\
\hline age $($ years $)$ & $68.64 \pm 16.78$ & $63.26 \pm 19.65$ & $62.92 \pm 19.22$ & $\mathrm{NS}$ \\
\hline fasting glycaemia $(\mathrm{mmol} / \mathrm{l})$ & $5.16 \pm 0.78$ & $5.04 \pm 0.94$ & $4.96 \pm 0.67$ & $\mathrm{NS}$ \\
\hline $\mathrm{C}$-peptide $(\mu \mathrm{g} / \mathrm{l})$ & $3.75 \pm 2.02$ & $3.58 \pm 2.21$ & $3.83 \pm 2.3$ & $\mathrm{NS}$ \\
\hline insulin $(\mathrm{mIU} / \mathrm{l})$ & $9.26 \pm 6.16$ & $11.95 \pm 12.76$ & $11.80 \pm 7.33$ & $\mathrm{NS}$ \\
\hline $\mathrm{HOMA} \mathrm{index}$ & $2.22 \pm 1.75$ & $3.06 \pm 3.86$ & $2.57 \pm 1.7$ & $\mathrm{NS}$ \\
\hline $\mathrm{HbA} / \mathrm{c}(\mathrm{mmol} / \mathrm{mol}))$ & $5.8(40) \pm 1.4(13)$ & $5.2(33) \pm 0.8(7)$ & $5.2(34) \pm 0.8(7)$ & $>0.05$ \\
\hline $\mathrm{BMI}\left(\mathrm{kg} / \mathrm{m}^{2}\right)$ & $27.0 \pm 6.76$ & $25.1 \pm 3.87$ & $24.4 \pm 4.21$ & $\mathrm{NS}$ \\
\hline
\end{tabular}

Tab. 2. Studies investigating the relationship between type II deiodinase Thr92Ala polymorphism and type 2 diabetes mellitus.

\begin{tabular}{|c|c|c|c|}
\hline Authors & Publication year & State (race or nation) & Results \\
\hline \multirow{2}{*}{ Mentuccia et al } & \multirow{2}{*}{2002} & \multirow{2}{*}{$\begin{array}{l}\text { USA } \\
\text { (Americans -Caucasians) }\end{array}$} & $\begin{array}{l}\text { higher risk of T2DM was confirmed in Ala-homozygotes in comparison with } \\
\text { Thr-homozygotes and heterozygotes }\end{array}$ \\
\hline & & & $\begin{array}{l}\text { non-diabetic Ala-homozygotes have higher HOMA index in comparison with } \\
\text { non-diabetic Thr-homozygotes and heterozygotes }\end{array}$ \\
\hline Canani et al & 2005 & Brasil (Brasilians) & $\begin{array}{l}\text { non-diabetic Ala-homozygotes have higher HOMA index in comparison with } \\
\text { non-diabetic Thr-homozygotes and heterozygotes }\end{array}$ \\
\hline Mentuccia et al & 2005 & USA (Amishes) & higher risk of T2DM was not confirmed in any group \\
\hline \multirow[b]{2}{*}{ Grarup et al } & \multirow[b]{2}{*}{2007} & \multirow[b]{2}{*}{ Denmark (Danes) } & higher risk of T2DM was not confirmed in any group \\
\hline & & & $\begin{array}{l}\text { non-diabetic Ala-homozygotes have higher fasting glyceamia levels in comparison } \\
\text { with non-diabetic Thr-homozygotes and heterozygotes }\end{array}$ \\
\hline Maia et al & 2007 & USA (Americans) & higher risk of T2DM was not confirmed in any group \\
\hline \multirow{2}{*}{ Dora et al } & \multirow{2}{*}{2010} & \multirow{2}{*}{ Brazil (Brazilians) } & $\begin{array}{l}\text { higher risk of T2DM was confirmed in Ala-homozygotes in comparison with } \\
\text { Thr-homozygotes and heterozygotes }\end{array}$ \\
\hline & & & $\begin{array}{l}\text { Ala-homozygotes with T2DM have higher } \mathrm{HbA}_{1 \mathrm{c}} \text { in comparison with Thr-homo- } \\
\text { zygotes and heterozygotes with T2DM }\end{array}$ \\
\hline Estivalet et al & 2011 & Brazil (Brazilians) & $\begin{array}{l}\text { Ala-homozygotes with T2DM have higher insulin resistance in comparison with } \\
\text { Thr-homozygotes and heterozygotes with T2DM }\end{array}$ \\
\hline Nair et al & 2012 & USA (Pima Indians) & $\begin{array}{l}\text { higher risk of T2DM was confirmed in Ala-homozygotes in comparison with } \\
\text { Thr-homozygotes and heterozygotes }\end{array}$ \\
\hline
\end{tabular}

References 2-6, 12-14 
790-792

Some studies demonstrated that the group most at risk for the development of DM2 are Ala-92 homozygotes. Mentuccia et al (2002), Dora et al (2010) and Nair et al (2012) observed higher risk of development of insulin resistance and later T2DM in Ala homozygotes in comparison with Thr homozygotes and heterozygotes $(2,4,6)$.

On the other hand, Mentuccia et al (2005), Grarup et al (2007), and Maia et al (2007) did not confirm higher prevalence of glycid metabolism disorders in any genotype group as compared with other two groups (12-14).

However, Grarup et al (2007) found higher fasting glycaemia levels in Ala homozygotes when compared to heterozygotes and Thr homozygotes in non-diabetic persons $(5.6 \pm 1.1$ vs $5.5 \pm 0.7$ vs $5.5 \pm 0.8 \mathrm{mmol} / \mathrm{l}$, respectively, $\mathrm{p}<0.05)(13)$.

Our findings are in conflict with those of Grarup et al (2007). We did not confirm significantly higher glycaemia serum levels in non-diabetic patients $(5.16 \pm 0.78$ vs $5.04 \pm 0.94$ vs $4.96 \pm 0.67$ $\mathrm{mmol} / \mathrm{l}$, respectively, $\mathrm{p}=0.24)$.

Dora et al (2010) in their study with 1,057 patients confirmed higher prevalence of Ala92Ala in non-diabetic persons $(p<0.05)$ (4) in contrast to our and Grarup's study.

Moreover, Dora et al (2010) also demonstrated higher fasting insulin levels in Ala92Ala subjects $(16.8 \pm 4.17$ vs $11.3 \pm 3.52$ $\mathrm{mIU} / 1$, respectively, $\mathrm{p}<0.01)(4)$.

We did not confirm the latter findings. Our patients with Ala92Ala genotype (52 (13\%)) had lower mean fasting plasma insulin level as compared to the rest of our group (348 $(87 \%))$, while the difference was not significant $(9.26 \pm 6.16$ vs $11.87 \pm 7.21 \mathrm{mIU} / \mathrm{l}$, respectively, $\mathrm{p}=0.53$ ).

In our study, insulin resistance evaluated by HOMA index was lower in Ala homozygotes when compared to the rest of our group. However, in contrast to Dora's study, the difference was statistically nonsignificant $(2.22 \pm 1.75$ vs $2.78 \pm 1.88, \mathrm{p}=0.54)$. Dora et al (2010) found significantly higher values of HOMA index in Ala92Ala when compared to Thr92Thr and Thr92Ala (8.5 \pm 3.11 vs $4.5 \pm 2.3$, respectively, $\mathrm{p}<0.01$ ) (4).

In our study, we demonstrated that $\mathrm{HbA}_{\mathrm{lc}}$ levels in Ala92 homozygotes were significantly higher than in other two groups (5.8 $(40) \pm 1.4(13)$ vs $5.2(33) \pm 0.8(7)$ vs $5.2(34) \pm 0.8(7) \%(\mathrm{mmol} /$ $\mathrm{mol}$ ), respectively, $\mathrm{p}=0.014$ ) (Tab.1). Also, Canani et al (2005) detected higher $\mathrm{HbA}_{1 \mathrm{c}}$ levels in non-diabetic Ala homozygotes, albeit with nonsignificant results $(7.1(54) \pm 2.33$ (23) vs 6.14 (44) \pm 1.95 (19) vs $6.49(47) \pm 2.08(20.4) \%(\mathrm{mmol} / \mathrm{mol})$, respectively, $\mathrm{p}=0.102)$ (3). Not even Maia et al (2007) found difference between serum $\mathrm{HbA}_{1 \mathrm{c}}$ levels $(5.7$ (39) \pm 1.0 (8.6) vs 5.7 (39) \pm 0.9 (7) vs $5.7(39) \pm 1.1(10) \%(\mathrm{mmol} / \mathrm{mol})$, respectively, $\mathrm{p}=0.6)(14)$.

\section{Conclusion}

Some studies claim that Ala-92 homozygotes of DII-Thr-92Ala polymorphism have higher risk of DM2 or higher mean values of glucose metabolism. Many factors induce development of DM2. Genetic influence has an important role, but external risk factors resulting from unhealthy lifestyle are dominant in the Slovak population. Our patients are older, obese (often as a component of metabolic syndrome) and polymorbid.
In summary, we can suppose that the genetic influence of DII-Thr92Ala polymorphism is possible, but in our subjects, this influence was overlapped by several other factors.

Further studies of larger populations are needed.

\section{References}

1. Bianco AC et al. Biochemistry, cellular and molecular biology, and physiological roles of the iodothyronine selenodeiodinases. Endocr Rev 2002; 23 (1): 38-89.

2. Mentuccia $D$ et al. Association between a novel variant of the human type 2 deiodinase gene Thr92Ala and insulin resistance: evidence of interaction with the Trp64Arg variant of the $\beta$-3-adrenergic receptor. Diabetes 2002; 51 (3): 880-883.

3. Canani LH et al. The type 2 deiodinase A/G (Thr92Ala) polymorphism is associated with decreased enzyme velocity and increased insulin resistance in patients with type 2 diabetes mellitus. J Clin Endocrinol Metab 2005; 90 (6): 3472-3478.

4. Dora JM et al. Association of the type 2 deiodinase Thr92Ala polymorphism with type 2 diabetes: case-control study and meta-analysis. Eur J Endocrinol 2010; 163 (3): 427-434.

5. Estivalet AAF et al. D2 Thr92Ala and PPAR $\gamma 2$ pro12ala polymorphisms interact in the modulation of insulin resistance in type 2 diabetic patients. Obesity 2011; 19 (4): 825-832.

6. Nair S et al. Association analyses of variants in the DIO2 gene with early-onset type 2 diabetes mellitus in Pima Indians. Thyroid 2012; 22 (1): 80-87.

7. Bianco AC, Kim, BW. Deiodinases: implications of the local control of thyroid hormone action. J Clin Invest 2006; 116 (10): 2571-2579.

8. Peeters RP et al. A new polymorphism in the type II deiodinase gene is associated with circulating thyroid hormone parameters. Am J Physiol Endocrinol Metab 2005; 289 (1): 75-81.

9. Torlontano M et al. Type 2 deiodinase polymorphism (Thr92Ala) predicts L-thyroxine dose to schieve target thyrotropin levels in thyroidectomized patients. J Clin Endocrinol Metab 2008; 93 (3): 910-913.

10. Thr92Ala Polymorphism of Human Type 2 Deiodinase Gene (hD2) Affects the Development of Graves' Disease, Treatment Efficiency, and Rate of Remission. https://www.hindawi.com/journals/jir/2012/340542//; 2012 (accessed 22 December 2017).

11. Weinstein SP, O’Boyle E, Haber RS. Thyroid Hormone Increases Basal and Insulin-Stimulated Glucose Transport in Skeletal Muscle. The Role of GLUT4 Glucose Transporter Expression. Diabetes. 1994; 43: 1185-1189.

12. Mentuccia D et al. The Thr92Ala deiodinase type 2 (DIO2) variant is not associated with type 2 diabetes or indices of insulin resistance in the Old Order of Amish. Thyroid 2005; 15 (11): 1223-1227.

13. Grarup $\mathbf{N}$ et al. Studies of the common DIO2 Thr92Ala polymorphism and metabolic phenotypes in 7342 Danish white subjects. J Clin Endocrinol Metab 2007; 92 (1): 363-366.

14. Maia AL et al. The type 2 deiodinase (DIO2) A/G polymorphism is not associated with glycemic traits: the Framingham Heart Study. Thyroid 2007; 17 (3): 199-202.

Received June 9, 2018. Accepted September 29, 2018. 